\title{
MIF from mussel: Coding sequence, phylogeny, polymorphism, 3D model and regulation of expression
}

\author{
Maria-Giovanna Parisi ${ }^{\mathrm{a}}$, Mylène Toubiana ${ }^{\mathrm{b}}$, Valentina Mangano ${ }^{\mathrm{a}}$, Nicolò Parrinello ${ }^{\mathrm{a}}$, \\ Matteo Cammarata ${ }^{\mathrm{a}}$, Philippe Roch ${ }^{\mathrm{b}, *}$ \\ a Marine Immunobiology Laboratory, University of Palermo, Via Archirafi 18, 90123 Palermo, Italy \\ ${ }^{\mathrm{b}}$ Ecologie des Systèmes Marins et Côtiers (EcoSym), CNRS-IRD-Université Montpellier 2, cc093, Place E. Bataillon, 34095 Montpellier cedex 05, France
}

\section{A R T I C L E I N F O}

\section{Article history:}

Received 26 August 2011

Revised 20 October 2011

Accepted 28 October 2011

Available online 4 November 2011

\section{Keywords:}

Macrophage

Cytokine

Gene regulation

Challenge

Bacteria

Fungus

q-PCR

Innate immunity

Mytilus

Mollusk

Bivalve

\begin{abstract}
A B S T R A C T
Three macrophage migration inhibitory factor (MIF)-related sequences were identified from a Mytilus galloprovincialis EST library. The consensus sequence included a 5'-UTR of 32 nucleotides, the complete ORF of 345 nucleotides, and a 3'-UTR of 349 nucleotides. As for other MIFs, M. galloprovincialis ORF does not include any signal or C-terminus extensions. The translated sequence of 115 amino acids possesses a molecular mass of 12,681.4, a pI of 6.27 and a stability index of 21.48. Its 3D structure resembles human MIF except for one shorter $\alpha$-helix. Although evolutionary separated from ticks and vertebrates, Mg-MIF appeared to be closely related to Pinctada fucata and Haliotis, but not to Chlamys farreri and Biomphalaria glabrata. Numerous mutation points were observed within the Mg-MIF ORF, defining 11 amino acid variants within the mussels from Palavas-France and 14 amino acid variants within the mussels from Palermo-Italy. The 2 major variants from Palavas were identical to 2 of the 4 major variants from Palermo. In all the $18 \mathrm{Mg}$-MIF variants, residues involved in tautomerase and in oxidoreductase activities were conserved. Generally, one mussel expressed $2 \mathrm{Mg}$-MIF amino acid sequences but with different frequencies of occurrence. Mg-MIF is constitutively expressed principally in hemocytes and in the mantle. In contrast to other animal models, Mg-MIF expression was always down regulated following challenge by bacteria and fungi, confirming previous data obtained with microarray. Down regulation started as soon as $1 \mathrm{~h}$ and $M g$-MIF expression returned to background 9-48 $\mathrm{h}$ after the challenge. Exception was regarding the yeast, Candida albicans, down-regulation between 9 and 72 h, suggesting yeast and bacteria-filamentous fungi trigger different mechanisms of elimination.
\end{abstract}

(C) 2011 Elsevier Ltd. All rights reserved.

\section{Introduction}

Cytokines are soluble mediators that play significant roles in immune reactions by means of inter-cellular/molecular processes. Numerous cytokines have been reported from diverse vertebrate species (reviewed by http://www.copewithcytokines.de for instance). The presence of cytokine-like activity or of related mRNA have also been observed in nearly all invertebrate species, including tunicates, echinoderms, annelids, nematodes, arachnids and insects (reviewed by (Beschin et al., 2001)). A recent paper reveals that the expression of a TNF $\alpha$-like gene is involved in ascidian inflammatory responses (Parrinello et al., 2008). In mollusks, first indirect evidences of cytokines were obtained by cross-reactions

Abbreviations: EST, expressed sequence tags; Mg-MIF, macrophage migration inhibitory factor from Mytilus galloprovincialis; ORF, open reading frame; UTR, untranslated region.

* Corresponding author. Tel.: +33 4671447 12; fax: +33 467144673 .

E-mail address: Philippe.Roch@univ-montp2.fr (P. Roch). with anti-cytokine antibodies, in vitro activities of vertebrate cytokines on invertebrate cells and activity of invertebrate sera on vertebrate cells (reviewed by (Canesi et al., 2006; Ottaviani, 2006)). To date, numerous EST-related to cytokines have been reported from the Pacific oyster, Crassostrea gigas (Gueguen et al., 2003; Roberts et al., 2008, 2009), the Mediterranean mussel, Mytilus galloprovincialis (Venier et al., 2003), the Bay scallop, Argopecten irradians irradians (Song et al., 2006) and the Antarctic bivalve, Laternula elliptica (Park et al., 2008b). Among these, only 2 cytokines have been analyzed. The first was TNF- $\alpha$-related factor from the Zhikong scallop, Chlamys farreri, the expression of which was up-regulated in hemocytes after $3 \mathrm{~h}$ in vitro contact with LPS (Yu et al., 2007), and from C. gigas, also up-regulated $12 \mathrm{~h}$ following in vivo challenge with a cocktail of four pathogenic Vibrio strains (Park et al., 2008a). The second was IL-17 from $C$. gigas, with rapid accumulation of transcript following challenge by immersion in a cocktail of heat-killed bacteria (Roberts et al., 2008, 2009).

Macrophage migration inhibitory factor (MIF) is a highly conserved protein, which exerts wide-ranged activities in vertebrates. 
It is a central mediator of innate immunity and has been shown to correlate with regulation of macrophage functions (Onodera et al., 1997), lymphocyte immunity (Abe et al., 2001) and a number of immune and inflammatory diseases (del Vecchio et al., 2000). As a consequence, more than 1000 scientific papers have been published on MIF, which is a ubiquitous mediator functioning as a cytokine, hormone or enzyme (Swope and Lolis, 1999). Its neuroendocrine role as mediator that increases the host response to microbial endotoxins suggested that MIF is at the crossroads between endocrine and immune systems (Bacher et al., 1998; Lafuente et al., 2009; Prieto-Lafuente et al., 2009). Indeed, MIF contributes to broad-spectrum immune and inflammatory responses (Chaisavaneeyakorn et al., 2005; Oddo et al., 2005) and is acting in immune evasion of some parasitic nematodes by modifying the activity of host cells (Pastrana et al., 1998; Wu et al., 2003). In addition, MIF exhibits several unusual features that distinguished this factor from typical cytokines, for example enzymatic thiol-protein oxidoreductase and tautomerase/isomerase activities (Kleemann et al., 1998).

MIF homologues have been detected in numerous animal species, from nematodes, ticks and echinoderms to jawless and jawed fishes, amphibians and chickens (Javeed et al., 2008), suggesting that this molecule has been conserved over 1 billion years of evolution. Only 4 cDNA sequences related to MIF have been reported so far from gastropods (Mitta et al., 2005; Wang et al., 2009a) and 2 from bivalves (Cui et al., 2011; Wang et al., 2009b). In addition, the role of MIF in the immune response against bacteria or parasites has been investigated only in the gastropods, Haliotis diversicolor (Wang et al., 2009a) and Biomphalaria glabrata (Baeza Garcia et al., 2010), and in the bivalve, Pinctada fucata (Cui et al., 2011).

In the present report, we (i) used 3 putative MIF sequences identified from a $M$. galloprovincialis EST library to establish the complete coding sequence and its phylogenetic relationships, (ii) constructed a 3D molecular model of the deduced protein, (iii) searched for polymorphism of Mg-MIF within and between M. galloprovincialis populations of distant geographic origins, and (iv) quantified the $M g$-MIF gene expression in various tissues and in hemocytes following in vivo challenges of the mussels.

\section{Materials and methods}

\subsection{Mussels and hemocyte collections}

Adult mussels, $M$. galloprovincialis (6-7 cm shell length), were purchased in July 2008 from the marine farm Les Compagnons de Maguelone, Palavas-France. Other mussels were purchased from Fazio Vivaio Miticoltura, Palermo-Italy, during July-September 2009. They were acclimated for $24 \mathrm{~h}$ in a flow-through system of oxygenated seawater before sampling. Hemolymph $(0.8 \mathrm{ml}$ per mussel) was collected from the posterior adductor muscle with a $1 \mathrm{ml}$ syringe containing $0.2 \mathrm{ml}$ of the anti-coagulant modified Alsever's solution buffer (Torreilles et al., 1999). Hemocytes were pelleted by $10 \mathrm{~min}$ centrifugation at $800 \mathrm{~g}, 4^{\circ} \mathrm{C}$.

\subsection{RNA extraction, reverse transcription, $P C R$ and $c D N A$ cloning}

Total RNA was extracted according to the Trizol Reagent protocol (Invitrogen), resuspended in $20 \mu \mathrm{l}$ of sterile distilled water and concentrations were measured on spectrophotometer ND-1000 (NanoDrop Technologies). First strand cDNAs were synthesized from $1 \mu \mathrm{g}$ of total RNA using hexaprimers (Invitrogen) and murine leukemia virus reverse transcriptase (Promega), and purified with Wizard SV Gel and PCR Clean-up System (Promega) then kept in sterile distilled water at $-20^{\circ} \mathrm{C}$ until use. Forward F2 and reverse
R3 PCR primers were hand-designed according to the consensus sequence constructed based on MGC03559, MGC08770 and MGC08785 (Fig. 1) from the M. galloprovincialis EST database Mg_NOR01 (Venier et al., 2009). PCR program included initial denaturing of $35 \mathrm{ng}$ cDNA template by $2 \mathrm{~min}$ at $94{ }^{\circ} \mathrm{C}$, followed by 30 cycles of denaturing at $94^{\circ} \mathrm{C}$ for $30 \mathrm{~s}$, annealing at $55^{\circ} \mathrm{C}$ for $30 \mathrm{~s}$ and elongation at $72{ }^{\circ} \mathrm{C}$ for $1 \mathrm{~min}$, and a final extension at $72{ }^{\circ} \mathrm{C}$ for $5 \mathrm{~min}$. The unique amplicon of 598 nucleotides was cloned in the plasmid pCR II TOPO from the TOPO TA Cloning kit (Invitrogen). Plasmids were isolated using Wizard Plus SV Miniprep (Promega) and specificity of inserts has been confirmed by sequencings performed by Millegen (Labèges-France). Transformed Escherichia coli colonies were individually transferred to deep agar containing Luria-Bertoni medium and $50 \mu \mathrm{g} / \mathrm{ml}$ kanamycin, in 96 well microtiter plates and sent to Agowa GmbH (BerlinGermany) for sequencing using M13 as universal primers. Each clone was double strand sequenced and the sequences corrected accordingly.

Regarding tissue expression patterns, total mRNA was extracted from hemocytes, and from dissected gills, hepatopancreas, mantle, muscle and foot from 12 mussels, and then mixed as 3 pools of 4 mussels for each tissue. Reverse transcription and PCR conditions were performed as above but with primers F5 and R1 (Fig. 1). Resulting amplifications of 202 base pairs were run in 1.5\% agarose gel. BET stained bands were photographed using the BioRad GelDoc XR and scanned under the AlphaEaseFC software (Alpha Innotech). Results are presented as the arithmetic mean of optical density of the 3 pools \pm SD. Data were analyzed with the Student's $t$-test for statistically significant difference $(p<0.05)$.

\subsection{Analysis of cDNA and of deduced amino acid sequences}

Several adjustments and comparisons have been made: (i) the nucleotides from up-stream and down-stream the primers, including the primer sequences, were removed, (ii) all the sequences were aligned using Multalin (http://bioinfo.genopole-toulouse.prd.fr/multalin/multalin.html) and clustered according to nucleotide sequences, (iii) UTRs were removed and coding sequences compared using Multalin, (iv) the different coding sequences were translated into pro-peptides (http://www. expasy.ch/tools/dna.html), and (v) the resulting amino acid sequences compared using Multalin. Isoelectric points and instability index were calculated by http://au.expasy.org/cgi-bin/protparam.html. Signal peptide prediction was analyzed using the SignalP-3.0 Server available at http://www.cbs.dtu.dk/services/ SignalP/.

\subsection{Phylogenetic relationships and structural analysis}

Sequences related to MIF from invertebrates and vertebrates were subjected to multiple alignments using Clustal-W program. Final sequence alignments were done using CLUSTAL-X v.1.81 29, the similarity shaded with GeneDoc v.2.6.002. A phylogenetic tree was constructed by the Neighbor-Joining method after 1000 bootstrap iterations using CLC workbench 6.4. The protein structural model was developed using the SWISS-MODEL and the SwissPDB Viewer (Arnold et al., 2006) using the human model as comparison (Sun et al., 1996).

\subsection{Challenges with bacteria and fungi}

Hemocyte cDNA samples of mussels challenged with one injection of bacteria (Vibrio splendidus LGP32, Vibrio anguillarum, Micrococcus lysodeikticus) were those previously used for analysis of lysozyme gene expression (Li et al., 2008). Fungal challenge consisted of one injection of $50 \mu \mathrm{l}$ of PBS- $\mathrm{NaCl}\left(2 \mathrm{mM} \mathrm{KH}_{2} \mathrm{HPO}_{4}\right.$, 
F2

\begin{tabular}{|c|c|c|c|c|c|c|c|c|c|c|c|c|c|c|c|c|c|c|}
\hline & TAGC & GGTA & TC'AC & SATL & I"TCA & $C A A$ & $C A A$ & $A A \perp 1$ & $\begin{array}{c}\text { ATG } \\
M\end{array}$ & $\begin{array}{c}\text { CCG } \\
P\end{array}$ & $\begin{array}{c}\mathrm{ACT} \\
\mathrm{T}\end{array}$ & $\begin{array}{c}\text { TTT } \\
\text { F }\end{array}$ & $\begin{array}{c}\text { GCC } \\
\text { A }\end{array}$ & $\begin{array}{c}\text { ATT } \\
\text { I }\end{array}$ & $\begin{array}{c}\text { TAC } \\
Y\end{array}$ & $\begin{array}{c}\mathrm{ACC} \\
\mathrm{T}\end{array}$ & $\begin{array}{c}\mathrm{AAT} \\
\mathrm{N}\end{array}$ & $\begin{array}{c}\text { CTT } \\
\mathrm{L}\end{array}$ \\
\hline $\mathrm{CT}$ & $\mathrm{AA} A$ & GAC & $\mathrm{AAA}$ & $\mathrm{ATT}$ & $\mathrm{CCT}$ & GGA & $A A C$ & $\mathrm{TTT}$ & TTG & CTA & GAT & GTT & TCA & AGT & TTT & $\mathrm{ATT}$ & GCT & $\mathrm{AAG}$ \\
\hline P & $\mathrm{K}$ & $\mathrm{D}$ & $\mathrm{K}$ & I & $P$ & G & $\mathrm{N}$ & $F$ & L & $\mathrm{L}$ & $\mathrm{D}$ & $\mathrm{V}$ & $S$ & $S$ & $F$ & I & A & $\mathrm{K}$ \\
\hline $\mathrm{GA}$ & $\mathrm{CTT}$ & GGA & $\mathrm{AAA}$ & CCA & GAA & AGT & TAT & GTT & $\mathrm{ACA}$ & GTC & AGG & GTA & CAC & $\mathrm{CCA}$ & GAC & CAA & ATG & ATG \\
\hline $\mathrm{R}$ & L & $G$ & $\mathrm{~K}$ & $\mathrm{P}$ & $\mathrm{E}$ & S & $\mathrm{Y}$ & V & $\mathrm{T}$ & $\mathrm{V}$ & $\mathrm{R}$ & $\mathrm{V}$ & $\mathrm{H}$ & P & $\mathrm{D}$ & $\mathrm{Q}$ & M & M \\
\hline \\
\hline GT & $\mathrm{CAT}$ & GGG & GGA & TCT & $\mathrm{ACT}$ & GAT & $\mathrm{CCC}$ & TGT & GGT & AGT & GTG & GAA & CTG & TAC & AGT & ATT & GGA & GCA \\
\hline$S$ & $\mathrm{H}$ & & G & $\mathrm{S}$ & $\mathrm{T}$ & $\mathrm{D}$ & $\mathrm{P}$ & $\mathrm{C}$ & G & $S$ & $\mathrm{~V}$ & $\mathrm{E}$ & $\mathrm{L}$ & $Y$ & $S$ & $I$ & $\mathrm{G}$ & A \\
\hline TA & GGA & $\mathrm{GAA}$ & AAG & AAC & AAG & GAA & CAT & TCT & AAA & GAA & ATT & GCA & GAT & TTT & ATA & GAG & $\mathrm{AAA}$ & $\mathrm{AAT}$ \\
\hline L & G & $\mathrm{E}$ & $\mathrm{K}$ & $N$ & K & $\mathrm{E}$ & $\mathrm{H}$ & S & K & $E$ & I & A & $\mathrm{D}$ & $\mathrm{F}$ & I & $\mathrm{E}$ & K & $\mathrm{N}$ \\
\hline TA & GGA & $\mathrm{ATT}$ & GCA & $C \bar{A} \bar{A}$ & GAT & AGA & TTT & TAT & GTG & $\mathrm{ACA}$ & TTT & GTG & GAT & TTA & GAA & AGA & GGA & $\mathrm{AAT}$ \\
\hline $\begin{array}{l}\text { L } \\
\text { R1 }\end{array}$ & G & I & A & $\mathrm{Q}$ & D & $\mathrm{R}$ & $F$ & $\mathrm{Y}$ & V & $\mathrm{T}$ & $F$ & $\mathrm{~V}$ & D & L & $\mathrm{E}$ & $\mathrm{R}$ & G & $\mathrm{N}$ \\
\hline GTA & GGT & CTC & $\mathrm{AAT}$ & GGA & $\mathrm{AAA}$ & $\mathrm{ACT}$ & TTT & GCC & CAA & TGA & ATAZ & ATATG & GTGGA & $\mathrm{ACATA}$ & ATAAT & TAATA & AATAG & GTAC \\
\hline & G & $\mathrm{L}$ & $\mathrm{N}$ & W & $\mathrm{K}$ & $\mathrm{T}$ & $F$ & A & $\mathrm{Q}$ & & & & & & & & & \\
\hline \multirow{2}{*}{\multicolumn{19}{|c|}{$\begin{array}{l}\text { ACAGATTATGTTAACCTTTTTGTGTCATTTTATGTTATTCCTGGCTTTGAAGATAACTACAAACAGTTGAATAAA } \\
\text { CCGTTGAAAGTTCATCATATGATAAAGAAATGAAGAGCATGACATTAGCTACATTGATTTTTGATTTTGTAATA }\end{array}$}} \\
\hline & & & & & \multicolumn{14}{|c|}{ R3 } \\
\hline
\end{tabular}

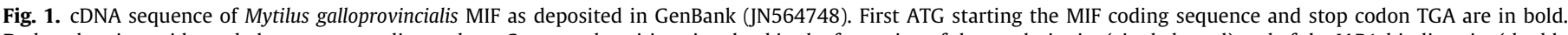

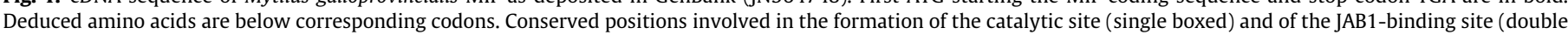

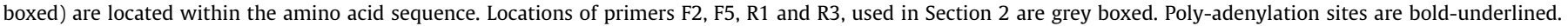

$10 \mathrm{mM} \mathrm{Na}_{2} \mathrm{HPO}_{4}, 3 \mathrm{mM} \mathrm{KCl}, 600 \mathrm{mM} \mathrm{NaCl}$ in distilled water, $\mathrm{pH}$ 7.4) containing $10^{4}$ spores of the filamentous fungus, Fusarium oxysporum, or of the yeast, Candida albicans, collected after 3 days of cultivation at room temperature on PDA (Potato Dextrose Agar, Sigma) in Petri dishes. Ten mussels per sampling end-point received injection into the posterior adductor muscle through a hole created by gentle filing on shells. After injection, mussels were returned to $20^{\circ} \mathrm{C}$ seawater. Sham injections consisted of $100 \mu \mathrm{l}$ of PBS- $\mathrm{NaCl}$ alone. Hemolymph ( $0.8 \mathrm{ml}$ per mussel) was collected from the posterior adductor muscle at $0,1,3,6,9,12,24,48$ and $72 \mathrm{~h}$ post-injection, in different batches of mussels each one being bled only one time, with a $1 \mathrm{ml}$ disposable syringe containing $0.2 \mathrm{ml}$ of anti-coagulant modified Alsever's solution. Hemolymph from 10 mussels were pooled and hemocytes pelleted by $10 \mathrm{~min}$ centrifugation at $800 \mathrm{~g}, 4^{\circ} \mathrm{C}$. RNA purification and reverse transcription were performed as in Section 2.2. The full process from injection to cDNA synthesis was repeated 4 times.

\section{6. q-PCR using the SYBR green chemistry}

Primer sequences used for MIF quantification were F5-R1 (Fig. 1). q-PCR mixture included: $1 \mu \mathrm{l}$ first strand cDNA (10 ng), $0.25 \mu \mathrm{l}$ of each specific primers at a concentration of $25 \mu \mathrm{M}$, $2.5 \mu \mathrm{l}$ of mix (Roche) containing FastStart Taq DNA polymerase, reaction buffer $2 \times$, dNTP mix, SYBR green 1 dye and $\mathrm{MgCl}_{2}$. The PCR program was started with initial Taq polymerase activation at $95{ }^{\circ} \mathrm{C}$ for $10 \mathrm{~min}$, followed by 50 cycles at $95{ }^{\circ} \mathrm{C}$ for $10 \mathrm{~s}, 62^{\circ} \mathrm{C}$ for $10 \mathrm{~s}$ and $72{ }^{\circ} \mathrm{C}$ for $15 \mathrm{~s}$. Melting temperatures were measured by returning to $62{ }^{\circ} \mathrm{C}$ for $30 \mathrm{~s}$ and gradual heating to $95^{\circ} \mathrm{C}$. Negative control reactions contained water in place of cDNA template and were included in each run to ensure absence of contamination. House keeping gene expression was represented by $28 \mathrm{~S}$ ribosomal RNA, using the forward primer 5'-AAGCGAGAAAAGAAACTAAC-3' and the reverse primer 5'-TTTACCTCTAAGCGGTTTCAC-3', as previously validated (Cellura et al., 2007; Li et al., 2008) with an annealing temperature of $65^{\circ} \mathrm{C}$. Calibration curves were obtained using 10 -fold serial dilutions of MIF or 28S rRNA amplicons in $10 \mu \mathrm{g}$ / $\mathrm{ml}$ sonicated salmon sperm DNA (Sigma).
Crossing point values expressed in cycle numbers were measured according to the threshold position of 4.2 and converted into Equivalent Target Amount (ETA) by the LightCycler 480 built-in software (Roche) using statistical calibration curves and the comparative $2^{-\Delta \Delta C t}$ method (Livak and Schmittgen, 2001). Expression levels of $M g$-MIF were calculated from the ratio of ETA for $M g$ MIF on ETA for $28 S$ rRNA. Normalization of ratios was calculated considering each ratio equal to 1 in unchallenged mussels and expressed as $x$-fold the ratio for unchallenged mussels. Data were presented as the arithmetic mean of 4 different experiments each one measured in quadruplicate \pm SEM. Normality of data distribution was assayed using the Shapiro-Wilk test available at http:// cran.fr.r-project.org. Student's $t$-test using $t$-Ease 2.8 ISI software has been employed to compare data of end-point with expression in unchallenged. Differences were considered significant for $p<0.05$.

\section{Results}

\subsection{Complete coding sequence of Mg-MIF}

Data mining of the M. galloprovincialis EST database Mg_NOR01 with MIF-like sequences from different organisms identified 3 sequences of 502, 681 and 724 nucleotides. None of these sequences included the poly-A tail. A consensus sequence was constructed and translated into amino acid sequence. Alignment of such amino acid sequence with several other molluscan MIF-related sequences found in database revealed the constant $\mathrm{NH}_{2}$ amino acid sequence

Table 1

Alignments of $\mathrm{NH}_{2}$ terminal amino acid sequences of Mollusk MIF-related sequences with the deduced consensus sequence constructed from the 3 Mytilus gall oprovincialis EST sequences revealing the position of the first methionine. Identical amino acids are grey boxed.

$\begin{array}{rr}\text { AVSRSSQAKIMPTFAIYTNLP. . . } & \text { Mytilus galloprovincialis (JN564748) } \\ \text { MPTFLLFTNLP... } & \text { Haliotis discus discus (FJ435176) } \\ \text { MPMFILYTNLP... } & \text { Lottia gigantea }(159446) \\ \text { MPCFILFTNVP. . . } & \text { Haliotis diversicolor (EU284114) }\end{array}$


Table 2

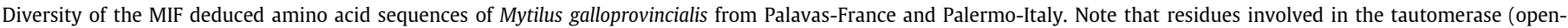

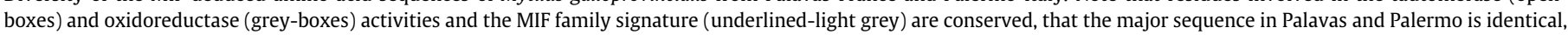

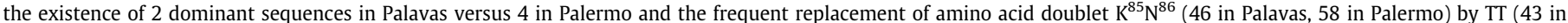
Palavas, 83 in Palermo)

\begin{tabular}{|c|c|c|}
\hline \multirow{3}{*}{ Deduced amino acid sequences } & \multicolumn{2}{|c|}{ Number of clones } \\
\hline & Palavas & Palermo \\
\hline & 89 clones & 141 clones \\
\hline MPTFAIYTNLPKDKIPGNFLLDASSFIAKRLGKPESYVTVRVHPDQMMSHGGSTDPCGSVELYSIGALGEKNKEHSKEIADFIEKNLGIAQDRFYVTFVDLERGNVGLNGKTFAQ & 34 & 29 \\
\hline 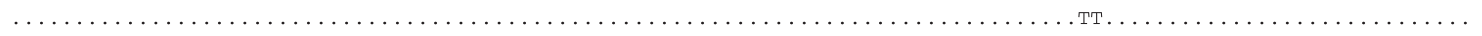 & 31 & 25 \\
\hline 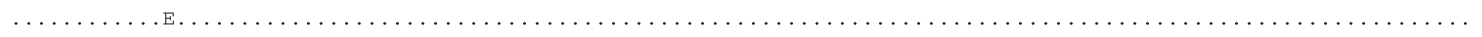 & 1 & 25 \\
\hline 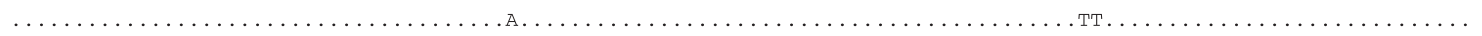 & & 21 \\
\hline 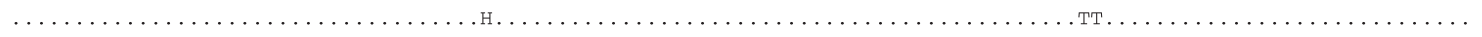 & & 12 \\
\hline 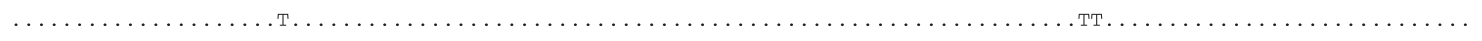 & & 11 \\
\hline 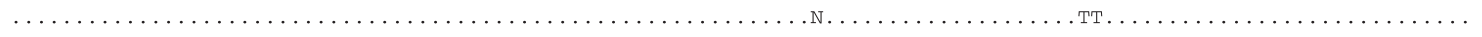 & & 8 \\
\hline 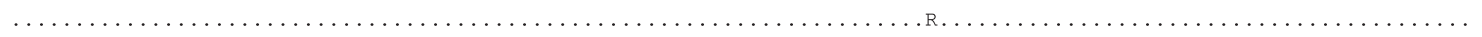 & 7 & 1 \\
\hline 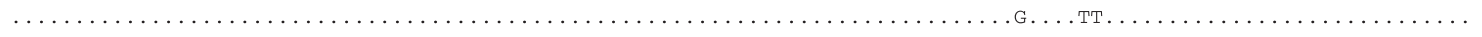 & 5 & 1 \\
\hline 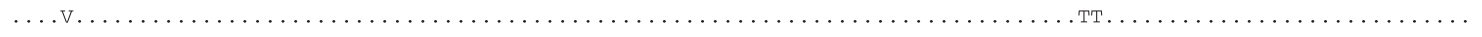 & 3 & \\
\hline 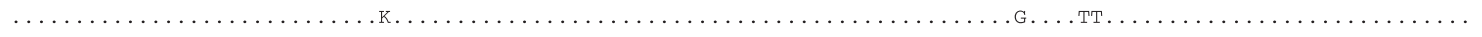 & 3 & \\
\hline 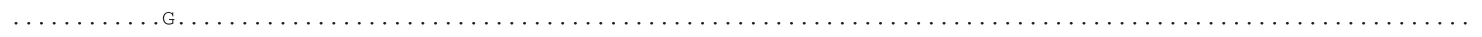 & 2 & 1 \\
\hline 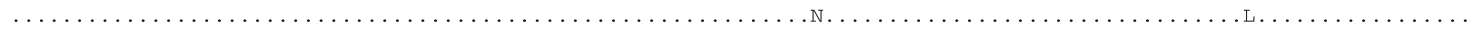 & & 2 \\
\hline 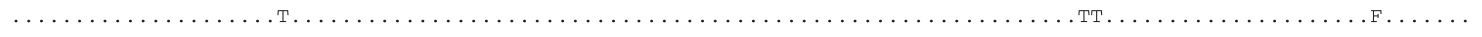 & & 2 \\
\hline 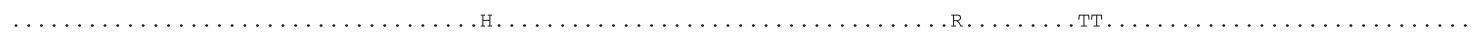 & & 2 \\
\hline 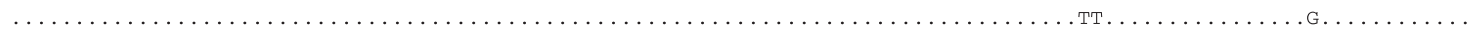 & 1 & 1 \\
\hline 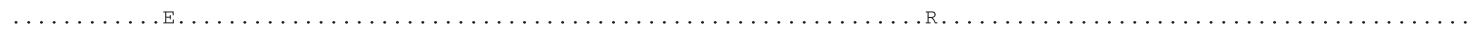 & 1 & \\
\hline 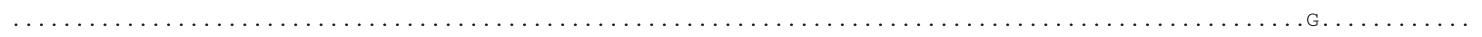 & 1 & \\
\hline
\end{tabular}

of MPxFxxxTNLP (Table 1). Consequently, the first methionine coded by nucleotides 33-35 was considered to be the first amino acid of the mature Mg-MIF protein. Computer analysis using the software Signal P3.0 Server failed to predict any signal peptide (not illustrated). Structure analysis of the consensus sequence of 729 nucleotides revealed the presence of an ORF coding for $115 \mathrm{ami}-$ no acids, with a 5'-UTR of 32 nucleotides and a 3'-UTR of 349 nucleotides including 2 poly-adenylation sites downstream the stop codon (Fig. 1). It was deposited in GenBank under the Accession No. JN564748 (released 03 September 2011). The protein of 115 amino acids corresponding to the major sequence from both Palavas and Palermo (Table 2) possesses a theoretical pI of 6.27 resulting from 14 negatively charged residues (D and E) and 13 positively charged residues ( $R$ and $K$ ) and a molecular mass of 12,681.4. The stability index of 21.48 classified the protein as stable although numerous theoretical cleavage sites were identified for pepsins, chymotrypsins, proteinase $K$ and thermolysin, but none for caspases. Catalytic sites $\mathrm{P}^{2}, \mathrm{~K}^{33}$ and $\mathrm{I}^{65}$ involved in the tautomerase motif, and $\mathrm{C}^{57} \mathrm{GSV}^{60}$ for oxydoreductase activity (Fig. 3), along with the MIF family signature $\mathrm{D}^{55}$ PCGSVELY(S/N)IGALG ${ }^{69}$ are conserved.

\subsection{Phylogenetic relationships}

Phylogeny reconstruction using BLAST analysis based on deduced amino acid sequences, revealed that $M g$-MIF sequence from Palavas presented the closest relationships with the bivalve $P$. fucata (Fig. 2). In fact, molluscan MIFs segregated into 2 clusters, mixing with gastropods and bivalves. Gastropod MIF sequences from Haliotis discus, $H$. diversicolor and Lottia gigantea are closely related but separated from $B$. glabrata, which is related to the bivalve, C. farreri. Vertebrate MIF were grouped in a homogeneous cluster including fishes and mammals. A third cluster is heterogeneous as grouping MIF sequences from diverse invertebrate phyla. Finally, echinoderm (Strongylocentrotus purpuratus) and urochordate (Ciona intestinalis) appeared among the molluscan MIF cluster but with some evolutionary distance. Computer analysis showed that bivalve MIF sequences are extremely stable proteins whereas gastropod MIF sequences are heterogeneous regarding theoretical
pI and stability: MIF from $H$. discus discus and from $L$. gigantea appeared surprisingly unstable (Table 3 ).

\section{3. $3 D$ modeling}

Fig. 3 shows the molecular model resulting from homology modeling process performed on basis of known human MIF molecular structure ( $e$-value $3.20 e-42$ ). $M g$-MIF was superimposed onto human MIF (SwissProt 1gd0B) revealing 39.5\% identity between the 2 structures. Mg-MIF possesses $2 \alpha$-helices and $6 \beta$-sheets as reported for human MIF chain B model (Sun et al., 1996). Oxidoreductase catalytic site and tautomerase motif are conserved. The main difference concerns the $\alpha$-helix between amino acids 6876, which is 7 amino acids shorten in Mg-MIF than in human MIF.

\subsection{Expression pattern in various tissues}

PCR was performed on RNA extracted from hemocytes and from various dissected tissues using primers F5-R1 (Fig. 1) stopping after 30 cycles of amplification. Clearly hemocytes presented the highest content on Mg-MIF mRNA, a level significantly different from gills $(1.67 \times$ folds $)$, hepatopancreas $(1.67 \times$ folds $)$, foot $(2.13 \times$ folds $)$ and muscle $(2.19 \times$ folds $)$, but not from the mantle (Fig. 4$)$.

\subsection{MIF sequence diversity among mussel populations}

PCR primers F2 and R3 (Fig. 1) were designed to amplify the complete coding sequence of $\mathrm{Mg}$-MIF cDNA prepared from hemocytes collected from one pool of 10 (Palavas-France) or 6 (Palermo-Italy) unchallenged mussels. Alignment of the amplicons obtained revealed many differences detailed below.

\subsubsection{M. galloprovincialis from Palavas-France}

Alignment of the nucleotide sequences obtained from 89 clones revealed 48 different sequences of 557 nucleotides in length. The ORF was of 345 nucleotides presenting 25 different sequences due to the presence of 21 mutation points among which 11 are silent (Supplemented Table 1), resulting in only 11 different peptides 


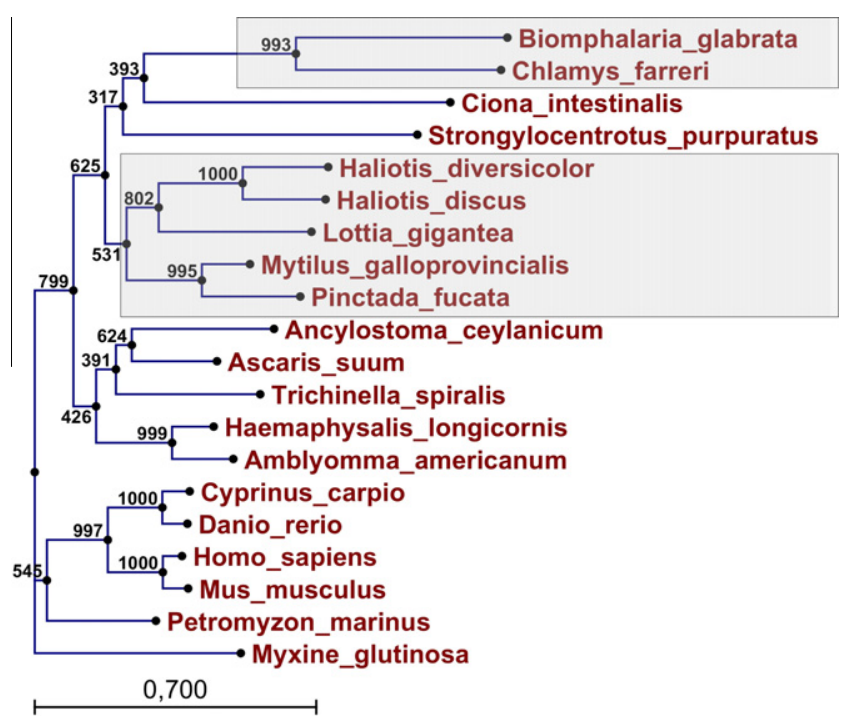

Fig. 2. Phylogenetic relationships between the deduced amino acid sequence of $M$. galloprovincialis MIF complete coding sequence and other MIF-related sequences found in databases. The respective GenBank accession numbers are as follows: Biomphalaria glabrata CK989824; Chlamys farreri DT716558.1; Ciona intestinalis XM002120850; Strongylocentrotus purpuratus XP001191035; Haliotis diversicolor EU284114; Haliotis discus discus FJ435176; Lottia gigantea Joint Genome Institute159446; Mytilus galloprovincialis JN564748; Pinctada fucata HQ448854; Ancylostoma ceylanicum EU442191; Ascaris suum AB158366; Trichinella spiralis AY050661; Haemaphysalis longicornis AB255601; Amblyomma americanum AF126688; Cyprinus carpio EU368584; Danio rerio BC171422; Homo sapiens CR456520; Mus musculus M010798; Petromyzon marinus APP33793; Myxine glutinosa APP33975. Note that mollusk MIF coding sequences segregated in 2 clusters, mixing bivalves and gastropods (boxed)

(Table 2). Two of these peptides appeared dominant, accounting for 65 of the 89 sequences. By contrast, 11 amino acid sequences differed from the major one by only one amino acid. Seven of the mutations resulted in replacements by equivalent amino acid. Finally, only 3 mutations corresponded to non-equivalent amino acid replacements, 2 (D by $E$ in position 13 ) found in 2 clones each and one ( $\mathrm{K}$ by $\mathrm{T}$ in position 85 ) found in nearly half the clones (Table 2). The first 6 nucleotides corresponding to the partial $5^{\prime}$-UTR did not reveal any variation. In contrast, the 3'-UTR of 199 nucleotides shared by 66 sequences of 89 , was highly variable including 30 mutation points. In addition, 7 sequences included deletion(s) and 16 sequences included addition(s) of nucleotides. Consequently, the 3'-UTR ranged from 196 to 208 nucleotides (data not shown).

\subsubsection{M. galloprovincialis from Palermo-Italy}

Alignment of the nucleotide sequences obtained from 141 clones revealed 41 different sequences of 557 nucleotides in length. The ORF was of 345 nucleotides presenting 33 different sequences due to the presence of 16 mutation points among which 5

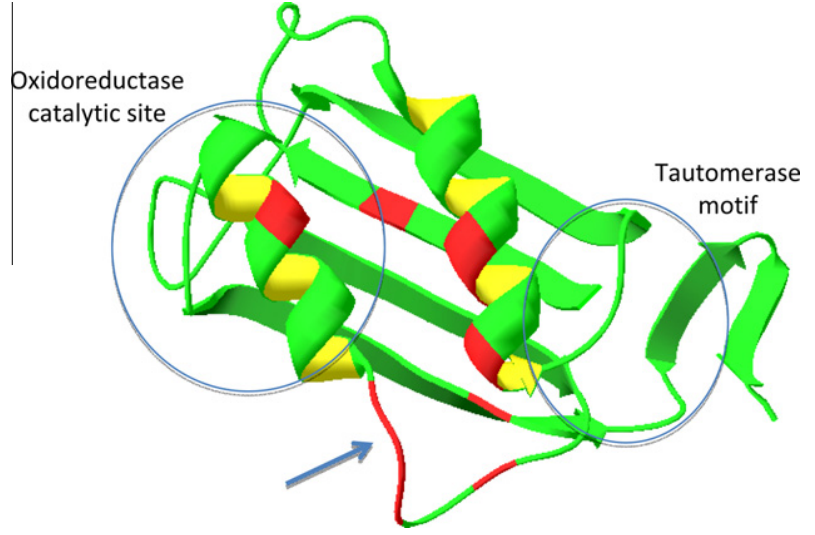

Fig. 3. 3D model structure of mussel MIF based on the template of human MIF available at PDB 1gdOB for human macrophage inhibition factor chain B. Homologies are in green, differences are in red. Note the conserved $2 \alpha$-helix and $6 \beta$ sheets, and the oxidoreductase and tautomerase putative sites (circles). The main difference concerned the length of one $\alpha$-helix, which is 7 amino acids shorter in $M g$-MIF (arrow). (For interpretation of the references to color in this figure legend, the reader is referred to the web version of this paper.)

are silent (Supplemented Table 1 ) resulting in 14 different peptides (Table 2). Four sequences appeared dominant, accounting for 100 of the 141 sequences. By contrast, 4 amino acid sequences were found in only one clone each. Five mutations resulted in replacements by equivalent amino acid and 7 mutations corresponded to non-equivalent amino acid replacements. As for the mussels from Palavas, the first 6 nucleotides corresponding to the partial 5'-UTR showed no variation. In contrast, the 3'-UTR of 199 nucleotides shared by 130 sequences of 141 was highly variable including 15 mutation points. In addition, 10 sequences presented deletion(s), of which one is of 37 consecutive nucleotides, and one sequence presented 7 extra nucleotides. Consequently, 3'-UTR ranged from 159 to 206 nucleotides (data not shown).

\subsubsection{Comparison between Palavas and Palermo sequences}

Only 7 of the 18 different amino acid sequences were common to both mussel populations (Table 2). The 2 major sequences from Palavas were also among the major sequences from Palermo. One of the other major Palermo sequences was found only once in Palavas, whereas the other 4 shared sequences were found 1-7 times. Amino acid residues involved in the tautomerase and oxidoreductase activities, as well as MIF family signature, are conserved. In addition, the 2 amino acids from positions 85-86 represented a hot-spot of mutation with the frequent replacement of the doublet $\mathrm{KN}$, found in 46 sequences from Palavas and in 58 from Palermo, by TT found in 43 sequences from Palavas and in 83 from Palermo.

\subsubsection{Comparison between individual mussels}

Mg-MIF cDNA was prepared from hemocytes collected from 6 individual mussels from Palermo. Mg-MIF complete coding

Table 3

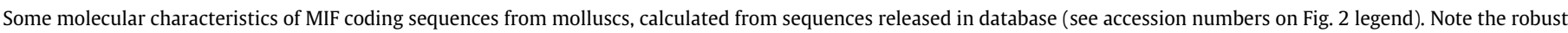
stability of bivalve sequences and the heterogeneity of gastropod MIFs regarding pI and stability.

\begin{tabular}{|c|c|c|c|c|}
\hline & Number of amino acids & Molecular mass & Estimated pI & Stability index \\
\hline \multicolumn{5}{|l|}{ Bivalves } \\
\hline Mytilus galloprovincialis & 115 & $12,681.4$ & 6.27 & 21.48 \\
\hline Chlamys farreri & 126 & $14,537.5$ & 6.51 & 24.46 \\
\hline Pinctada fucata & 119 & $13,259.2$ & 5.87 & 25.19 \\
\hline \multicolumn{5}{|l|}{ Gastropods } \\
\hline Haliotis diversicolor & 127 & $14,016.1$ & 6.90 & 35.33 \\
\hline Haliotis discus discus & 119 & $13,372.5$ & 5.91 & 55.53 \\
\hline Biomphalaria glabrata & 118 & $13,227.5$ & 8.75 & 34.56 \\
\hline Lottia gigantea & 121 & $13,426.5$ & 5.90 & 44.41 \\
\hline
\end{tabular}




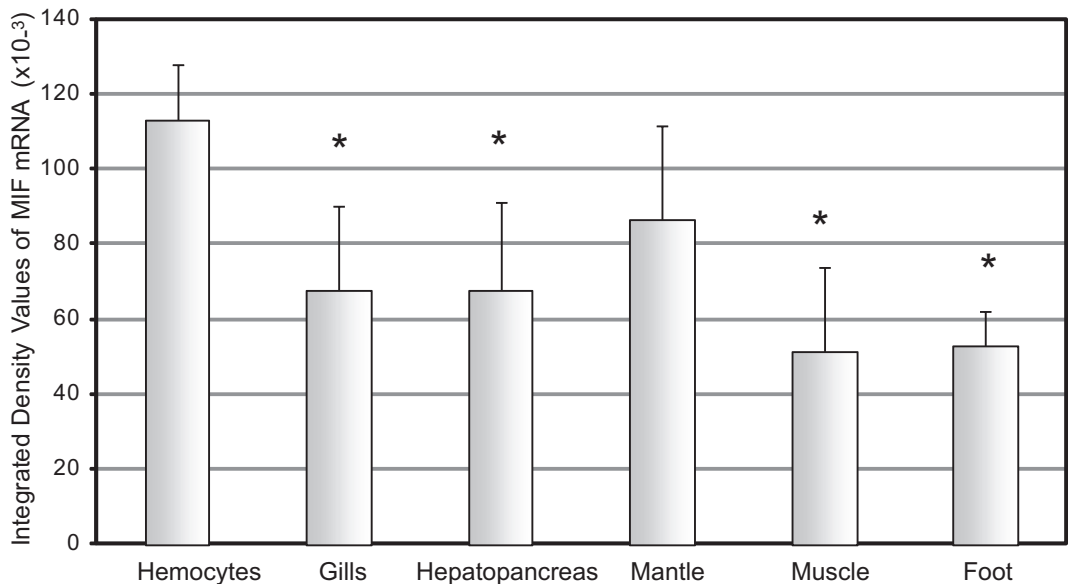

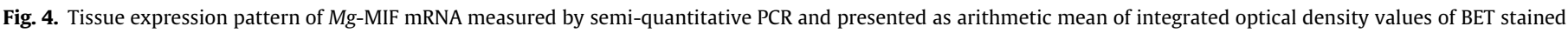

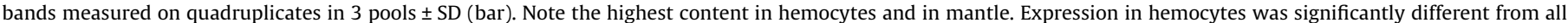
other tissues $\left({ }^{*} p<0.05\right)$ except from mantle.

Table 4

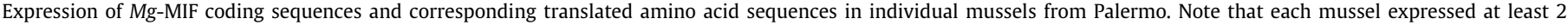
coding sequences with the corresponding translated amino acid sequences, and that frequencies of occurrence of such amino acid sequences are extremely variable.

\begin{tabular}{|c|c|c|c|c|}
\hline \multirow[t]{2}{*}{ Mussel name } & \multirow[t]{2}{*}{ Number of MIF sequenced clones } & \multicolumn{2}{|c|}{ Number of different sequences } & \multirow[t]{2}{*}{$\%$ of amino acid sequences } \\
\hline & & Coding sequences & Amino acids & \\
\hline \multirow[t]{2}{*}{$12 \mathrm{~L}$} & 30 & 2 & 2 & 54 \\
\hline & & & & 46 \\
\hline \multirow[t]{2}{*}{$14 \mathrm{~L}$} & 29 & 2 & 2 & 55 \\
\hline & & & & 45 \\
\hline \multirow[t]{3}{*}{$1 \mathrm{~S}$} & 25 & 4 & 3 & 80 \\
\hline & & & & 16 \\
\hline & & & & 4 \\
\hline \multirow[t]{2}{*}{$5 \mathrm{~S}$} & 29 & 2 & 2 & 62 \\
\hline & & & & 38 \\
\hline \multirow[t]{2}{*}{$14 \mathrm{~S}$} & 30 & 2 & 2 & 70 \\
\hline & & & & 30 \\
\hline \multirow[t]{2}{*}{$15 \mathrm{~S}$} & 16 & 2 & 2 & 87 \\
\hline & & & & 13 \\
\hline
\end{tabular}

sequences were amplified with the primers F2-R3 and 16-30 clones per mussel have been randomly double strand sequenced. Two MIF coding sequences were obtained from 5 mussels, which gave rise to 2 translated amino acid sequences (Table 4). Frequencies of such amino acid sequences were extremely variable, from nearly equally represented up to one sequence present in $87 \%$ of the clones. Four MIF coding sequences were obtained from the mussel 1S; translation into amino acids revealed only 3 sequences, one was present in $80 \%$ of the sequenced clones.

\subsection{Expression following challenges}

Mg-MIF expression has been quantified by q-PCR using the primers F5-R1 applied to hemocytes collected from mussels challenged by one injection of bacteria, fungi or PBS-NaCl (Fig. 5). Injection of both $V$. splendidus and $V$. anguillarum resulted in a significant decrease of MIF mRNA as soon as $1 \mathrm{~h}$ post-injection, and still significantly lower at $24 \mathrm{~h}$. Injection of $M$. lysodeikticus induced similar decrease although non-statistically significant between 3 and $9 \mathrm{~h}$ post-injection. In the 3 bacteria-injected samples, return to background expression occurred 2 days post-injection. Regarding injections of fungi, the response of MIF gene was contrasted: early significant decrease induced by $F$. oxysporum returning to background $9 \mathrm{~h}$ post-injection, versus late decrease induced by C. albicans. The latest was the only challenge with delayed effect starting $9 \mathrm{~h}$ post-injection and lasting at least 3 days. Unexpected was the decrease observed in the first hours following saline injection although considered as a control sham injection.

\section{Discussion}

MIF is a peculiar cytokine and many questions about it remain unclear. One of them is related to the absence of signal peptide reported in murine, human and fish MIF sequences, as we observed in M. galloprovincialis. Thus, evidence suggested that MIF does not travel to the endoplasmic reticulum, instead it is secreted via a non-classical export pathway involving an ATP binding cassette transporter (Flieger et al., 2003). MIF is part of the growing list of cytokines, such as interleukin-1 (IL-1) and basic fibroblast growth factor (bFGF), which are released from cells by non-classical pathways. No $\mathrm{COOH}$-terminus extension was also reported for any MIFrelated sequences, making MIF ORF a sequence coding directly for the active peptide, and not including a precursor. Computer analysis of the 115 amino acids resulting from translation of $M g$-MIF mRNA revealed a stable protein with molecular mass and pI similar to the ones of abalone, $H$. diversicolor, and $H$. discus discus. However, the later was evaluated as unstable. Two other MIF-related sequences identified in the Zhikong scallop, C. farreri (Wang et al., $2009 \mathrm{~b}$ ), and in the freshwater gastropod, B. glabrata, do not match the previous characteristics and reveal poor alignment, even between them. Consequently, although claimed as a highly conserved molecule, molluscan MIF appeared diverse, even within bivalves and within gastropods. 

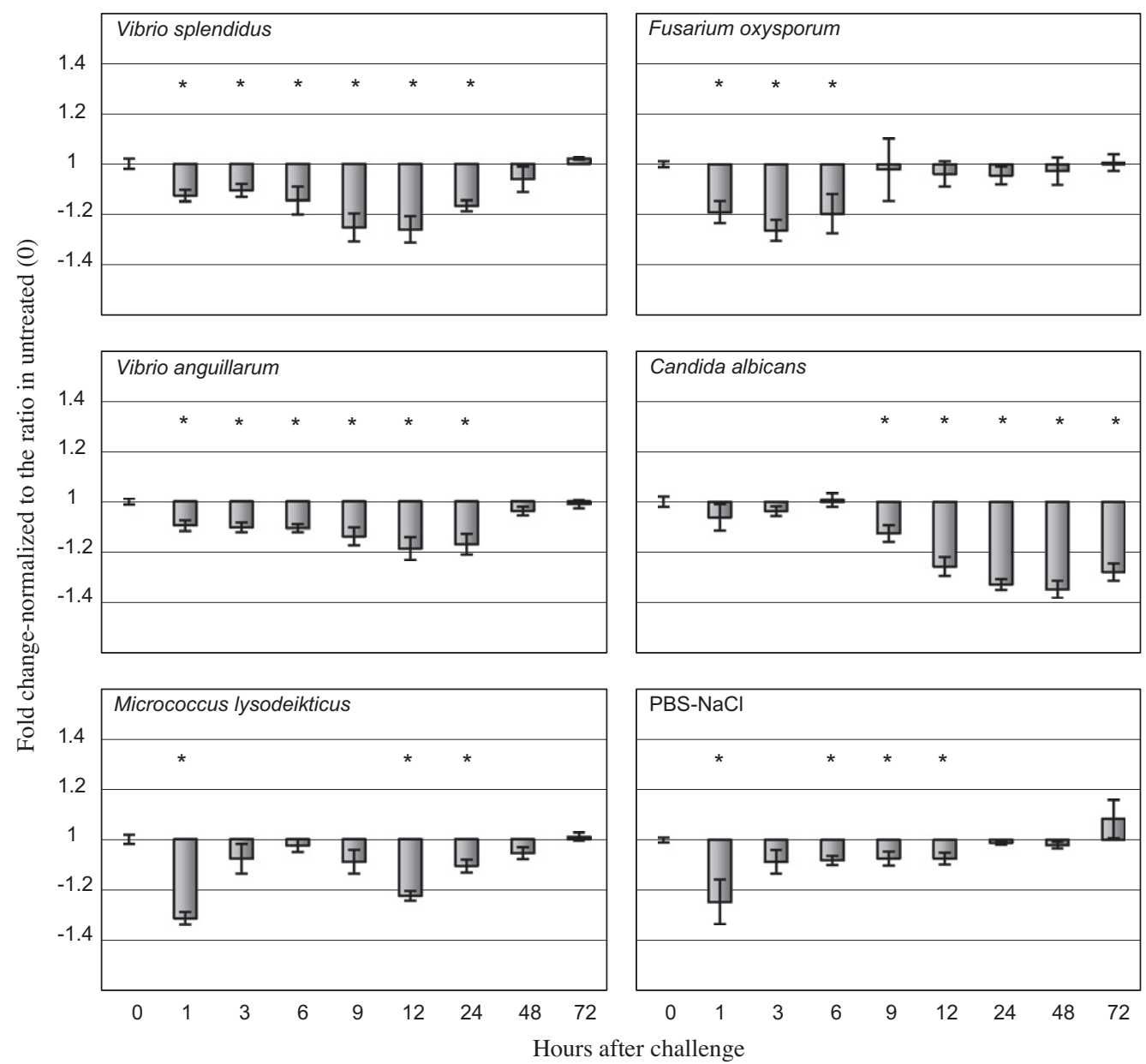

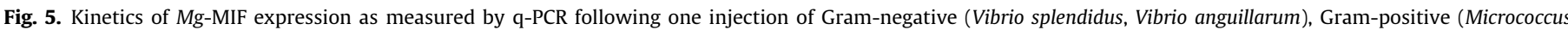

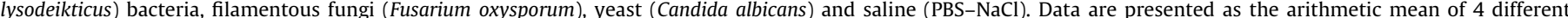

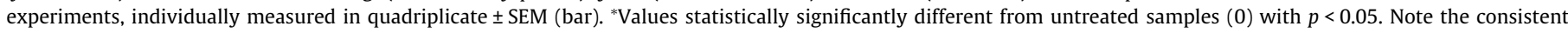

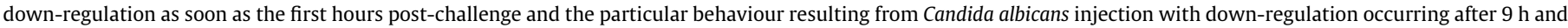
lasting at least 3 days.

MIF from the mollusks, $B$. glabrata, $H$. diversicolor and $P$. fucata, shared only $30 \%$ sequence similarity but high sequence and structural homologies with other members of the MIF vertebrate family (Cui et al., 2011). This includes residues, which are invariant across the whole MIF family, or involved in tautomerase and oxydoreductase activities, including in Mg-MIF. By contrast, cysteine patterns are extremely variable, from the unique cysteine in position 57 present in Mg-MIF, in the pearl oyster, P. fucata, in the Chinese mitten crab, Eriocheir sinensis, and in the protozoan parasite, Perkinsus marinus, MIF sequences, to the 4 cysteines of the Atlantic hagfish, Myxine glutinosa, and 3 in mammals. As a consequence, the cysteine array cannot be considered as a structural motif useful for MIF identification and/or molecular evolution.

To go deeper into the relationships of $M g$-MIF, we searched for 3D structural homology with established MIF molecular models deposited in databank. The putative molecular modeling of $\mathrm{Mg}$ MIF had similar structure to that of human MIF chain B including the $2 \alpha$-helices and $6 \beta$-sheets. In addition to minor differences in amino acid replacements along the sequence, the major difference occurred on the length of the $\alpha$-helix between tautomerase and oxidoreductase sites. This $\alpha$-helix is 7 amino acids shorter in Mg-MIF compared to the human counterpart (Sun et al., 1996).

In vertebrates, MIF is constitutively expressed by a variety of cells and tissues, including monocytes and macrophages and some endocrine and epithelial cells (Roger et al., 2007). It is rapidly released into the circulation from pre-formed intracellular vesicles by a non conventional leaderless pathway (Benigni et al., 2000), particularly after exposure to toxins and microbial cell wall components and pro-inflammatory mediators in response to stress (Bacher et al., 1998). We demonstrated that Mg-MIF is constitutively expressed in various tissues, but preferentially in hemocytes and mantle containing the gonads in mussels. Hemocytes infiltrate all tissues due to the mussel open circulatory system. As a consequence, it is not surprising to observe some MIF mRNA in all tissues. In all other animal models, MIF was also found as constitutively expressed in multiple organs, such are digestive tract, heart, hepatopancreas, foot and hemocytes from B. glabrata (Garcia et al., 2010) and the pearl oyster P. fucata (Cui et al., 2011), hepatopancreas, muscle, ovary, gill and mantle from the abalone, $H$. diversicolor (Wang et al., 2009a). In the gastropod, $B$. glabrata, MIF was found in vitro to be more abundant in spreading granulocytes showing pseudopods, the hemocyte subpopulation involved in immune response, than in non spreading hemocytes or hyalinocytes (Baeza Garcia et al., 2010) suggesting a role in the immune response. Also in fish, MIF transcripts are ubiquitously and constitutively expressed in several healthy tissues, as brain, liver, blood, gill, spleen, muscle, stomach, head kidney and heart. High constitutive expression in brain, joined to significant inducible capability revealed the neuroendocrine mediator role of MIF (Mao et al., 2010). 
Mussels from Palavas and from Palermo expressed several MIF mRNA variants, some of them being translated in different amino acid sequences. Meanwhile, in both locations, 2 and 4 sequences of 11 and 14, respectively, are more frequent. Among the remaining amino acid sequences, 9 were encountered only once or twice. Several other proteins were previously reported as highly polymorphic in mussels: antimicrobial peptides defensin, mytilin (Parisi et al., 2009) and particularly myticin (Costa et al., 2009; Pallavicini et al., 2008), C1q-like (Gerdol et al., 2011; Gestal et al., 2010), FREPs (Romero et al., 2011) and antifungal mytimycin (Sonthi et al., 2011). Although not understood, no doubt that the existence of numerous variants probably corresponds to as yet undefined functional mechanism(s).

Discovered almost 40 years ago as a T-cell cytokine, MIF is a critical mediator of septic shock as demonstrated in TNF $\alpha$ knockout mice and confirmed by the presence of high concentrations of MIF in the plasma of human patients with severe sepsis or septic shock (Calandra et al., 2000). Rapidly released by macrophages after stimulation with bacterial endotoxins and exotoxins, MIF stimulates the production of pro-inflammatory mediators by immune cells. Indeed, MIF-deficient macrophages were shown to be hypo responsive to stimulation with LPS and Gram-negative bacteria (Roger et al., 2003). Conversely, serum MIF concentration is high in patients with pulmonary tuberculosis and in HIV seropositive human (Kibiki et al., 2007). After endogenous glucocorticoïds or stress stimulation, increase in cellular MIF content was detected within 12-24 h in immunological and endocrine organs, and after $96 \mathrm{~h}$ in skin and muscle. Since MIF mRNA expression did not change, it has been hypothesized that increase in cellular MIF content resulted from post-transcriptional regulatory mechanisms (Fingerle-Rowson et al., 2003).

Regarding invertebrates, constant observations concerned up regulation of MIF expression following various challenges. Injection of $V$. anguillarum resulted in 5- to 10 -fold up regulation in hepatopancreas after 6-12 h, and 6- to 17-fold in hemocytes after 4-8 $\mathrm{h}$ in the Chinese mitten crab, E. sinensis (Li et al., 2011b). In both ticks, Haemaphysalis longicornis and Amblyomma americanum, MIF expression was up regulated during blood feeding (Bowen et al., 2010; Umemiya et al., 2007). In the gastropod abalone, $H$. diversicolor, MIF expression level in hepatopancreas was about 2 -fold up regulated at 24 and $48 \mathrm{~h}$ after Vibrio parahemolyticus injection (Wang et al., 2009a). Also in the bivalves C. farreri and $P$. fucata, expression of MIF was significantly up regulated in hemocytes at 6, 24 and $48 \mathrm{~h}$ after LPS treatment (Li et al., 2011a) and $8 \mathrm{~h}$ after injection of Vibrio alginolyticus (Cui et al., 2011). Our results did not match this pattern as we reported a rapid and general down regulation of $M g$-MIF expression in hemocytes whatever the challenge: bacteria, fungi or even saline injection.

Fortunately, our data are in agreement with previous observations performed on mussel hemocytes injected with $V$. splendidus at 3 and $48 \mathrm{~h}$ and measured by running a DNA microarray, i.e. a totally different technique eliminating eventual bias due to q-PCR technology (Venier et al., 2011). We controlled that down regulation of myticin and up regulation of defensin (data not shown) evolved in the present bacterial challenged samples as previously observed (Cellura et al., 2007), validating the general down regulation we reported for Mg-MIF. Although difficult to understand, $M g$-MIF does not behave as in other animal models. One can hypothesize that the MIF gene and/or hemocytes expressing MIF are involved in mussels in other yet non-elucidated innate mechanism(s) resulting in the observed down regulation.

\section{Acknowledgements}

Authors are grateful to Paola Venier from University of Padova (Italy) and to Alberto Pallavicini from University of Trieste (Italy) for providing the EST $M g$-MIF-related sequences, and for critical reading of the manuscript. Thanks to Molruedee Sonthi (Ph.D. student) for challenging the mussels with fungi, to Romain Gros for technical assistance and to Professor Edwin L. Cooper from UCLA for editing the manuscript. This work was partially supported by the EU program BIVALIFE (KBBE-2010-266157), the PICS CNRS No. 5197 with the University of Palermo-Italy, and the INTERLINK program from the Italian Ministry of Education.

\section{Appendix A. Supplementary data}

Supplementary data associated with this article can be found, in the online version, at doi:10.1016/j.dci.2011.10.014.

\section{References}

Abe, R., Peng, T., Sailors, J., Bucala, R., Metz, C.N., 2001. Regulation of the CTL response by macrophage migration inhibitory factor. J. Immunol. 166, 747-753.

Arnold, K., Bordoli, L., Kopp, J., Schwede, T., 2006. The SWISS-MODEL workspace: a web-based environment for protein structure homology modelling. Bioinformatics 22, 195-201.

Bacher, M., Meinhardt, A., Lan, H.Y., Dhabhar, F.S., Mu, W., Metz, C.N., Chesney, J.A., Gemsa, D., Donnelly, T., Atkins, R.C., Bucala, R., 1998. MIF expression in the rat brain: implications for neuronal function. Mol. Med. 4, 217-230.

Baeza Garcia, A., Pierce, R.J., Gourbal, B., Werkmeister, E., Colinet, D., Reichhart, J.M. Dissous, C., Coustau, C., 2010. Involvement of the cytokine MIF in the snail host immune response to the parasite Schistosoma mansoni. PLoS Pathog., 6.

Benigni, F., Atsumi, T., Calandra, T., Metz, C., Echtenacher, B., Peng, T., Bucala, R. 2000. The proinflammatory mediator macrophage migration inhibitory factor induces glucose catabolism in muscle. J. Clin. Invest. 106, 1291-1300.

Beschin, A., Bilej, M., Torreele, E., De Baetselier, P., 2001. On the existence of cytokines in invertebrates. Cell. Mol. Life Sci. 58, 801-814.

Bowen, C.J., Jaworski, D.C., Wasala, N.B., Coons, L.B., 2010. Macrophage migration inhibitory factor expression and protein localization in Amblyomma americanum (Ixodidae). Exp. Appl. Acarol. 50, 343-352.

Calandra, T., Echtenacher, B., Roy, D.L., Pugin, J., Metz, C.N., Hultner, L., Heumann, D., Mannel, D., Bucala, R., Glauser, M.P., 2000. Protection from septic shock by neutralization of macrophage migration inhibitory factor. Nat. Med. 6, 164-170.

Canesi, L., Betti, M., Ciacci, C., Lorusso, L.C., Pruzzo, C., Gallo, G., 2006. Cell signaling in the immune response of mussel hemocytes. Invert. Survey J. 3, 40-49.

Cellura, C., Toubiana, M., Parrinello, N., Roch, P., 2007. Specific expression of antimicrobial peptide and HSP70 genes in response to heat-shock and several bacterial challenges in mussels. Fish Shellfish Immunol. 22, 340-350.

Chaisavaneeyakorn, S., Lucchi, N., Abramowsky, C., Othoro, C., Chaiyaroj, S.C., Shi, Y.P., Nahlen, B.L., Peterson, D.S., Moore, J.M., Udhayakumar, V., 2005 Immunohistological characterization of macrophage migration inhibitory factor expression in Plasmodium falciparum-infected placentas. Infect. Immun. 73, 3287-3293.

Costa, M.M., Dios, S., Alonso-Gutierrez, J., Romero, A., Novoa, B., Figueras, A., 2009. Evidence of high individual diversity on myticin C in mussel (Mytilus galloprovincialis). Dev. Comp. Immunol. 33, 162-170.

Cui, S., Zhang, D., Jiang, S., Pu, H., Hu, Y., Guo, H., Chen, M., Su, T., Zhu, C., 2011. A macrophage migration inhibitory factor like oxidoreductase from pearl oyster Pinctada fucata involved in innate immune responses. Fish Shellfish Immunol. 31, 173-181.

del Vecchio, M.T., Tripodi, S.A., Arcuri, F., Pergola, L., Hako, L., Vatti, R., Cintorino, M., 2000. Macrophage migration inhibitory factor in prostatic adenocarcinoma: correlation with tumor grading and combination endocrine treatment-related changes. Prostate 45, 51-57.

Fingerle-Rowson, G., Koch, P., Bikoff, R., Lin, X., Metz, C.N., Dhabhar, F.S., Meinhardt, A., Bucala, R., 2003. Regulation of macrophage migration inhibitory factor expression by glucocorticoids in vivo. Am. J. Pathol. 162, 47-56.

Flieger, O., Engling, A., Bucala, R., Lue, H., Nickel, W., Bernhagen, J., 2003. Regulated secretion of macrophage migration inhibitory factor is mediated by a nonclassical pathway involving an ABC transporter. FEBS Lett. 551, 78-86.

Garcia, J.S., Maldonado Junior, A., Bidau, C.J., Correa Ldos, R., Lanfredi, R.M., Coelho, P.M., 2010. The effect of early infection with Echinostoma paraensei on the interaction of Schistosoma mansoni with Biomphalaria glabrata and Biomphalaria tenagophila. Mem. Inst. Oswaldo Cruz 105, 499-503.

Gerdol, M., Manfrin, C., De Moro, G., Figueras, A., Novoa, B., Venier, P., Pallavicini, A., 2011. The C1q domain containing proteins of the Mediterranean mussel Mytilus galloprovincialis: a widespread and diverse family of immune-related molecules. Dev. Comp. Immunol. 35, 635-643.

Gestal, C., Pallavicini, A., Venier, P., Novoa, B., Figueras, A., 2010. MgC1q, a novel C1q-domain-containing protein involved in the immune response of Mytilus galloprovincialis. Dev. Comp. Immunol. 34, 926-934.

Gueguen, Y., Cadoret, J.P., Flament, D., Barreau-Roumiguiere, C., Girardot, A.L., Garnier, J., Hoareau, A., Bachere, E., Escoubas, J.M., 2003. Immune gene discovery by expressed sequence tags generated from hemocytes of the bacteria-challenged oyster, Crassostrea gigas. Gene 303, 139-145. 
Javeed, A., Zhao, Y., Zhao, Y., 2008. Macrophage-migration inhibitory factor: role in inflammatory diseases and graft rejection. Inflamm. Res. 57, 45-50.

Kibiki, G.S., van der Ven, A.J., Geurts-Moespot, A., Shao, J., Calandra, T., Sweep, F.C., Dolmans, W.M., 2007. Serum and BAL macrophage migration inhibitory factor levels in HIV infected Tanzanians with pulmonary tuberculosis or other lung diseases. Clin. Immunol. 123, 60-65.

Kleemann, R., Kapurniotu, A., Frank, R.W., Gessner, A., Mischke, R., Flieger, O., Juttner, S., Brunner, H., Bernhagen, J., 1998. Disulfide analysis reveals a role for macrophage migration inhibitory factor (MIF) as thiol-protein oxidoreductase. J. Mol. Biol. 280, 85-102.

Lafuente, L., Gregory, W., Allen, J., Maizels, R., 2009. MIF homologues from a filarial nematode parasite synergize with IL- 4 to induce alternative activation of host macrophages. J. Leukoc. Biol., 85.

Li, F., Huang, S., Wang, L., Yang, J., Zhang, H., Qiu, L., Li, L., Song, L., 2011a. A macrophage migration inhibitory factor like gene from scallop Chlamys farreri: involvement in immune response and wound healing. Dev. Comp. Immunol. 35, 62-71.

Li, H., Parisi, M.G., Toubiana, M., Cammarata, M., Roch, P., 2008. Lysozyme gene expression and hemocyte behaviour in the Mediterranean mussel, Mytilus galloprovincialis, after injection of various bacteria or temperature stresses. Fish Shellfish Immunol. 25, 143-152.

Li, W.W., Jin, X.K., He, L., Wang, Y., Chen, L.L., Jiang, H., Wang, Q., 2011b. Molecular cloning, characterization and expression analysis of macrophage migration inhibitory protein (MIF) in Chinese mitten crab, Eriocheir sinensis. Fish Shellfish Immunol. 30, 324-329.

Livak, K.J., Schmittgen, T.D., 2001. Analysis of relative gene expression data using real-time quantitative PCR and the 2(-Delta Delta $C(T)$ ) method. Methods 25, 402-408.

Mao, Y., Xu, B., Su, Y., Zhang, Z., Ding, S., Wang, D., Wang, J., 2010. Cloning and mRNA expression of macrophage migration inhibitory factor (MIF) gene of large yellow croaker (Pseudosciaena crocea). Acta Oceanol. Sinica 29, 63-73.

Mitta, G., Galinier, R., Tisseyre, P., Allienne, J.F., Girerd-Chambaz, Y., Guillou, F., Bouchut, A., Coustau, C., 2005. Gene discovery and expression analysis of immune-relevant genes from Biomphalaria glabrata hemocytes. Dev. Comp. Immunol. 29, 393-407.

Oddo, M., Calandra, T., Bucala, R., Meylan, P.R., 2005. Macrophage migration inhibitory factor reduces the growth of virulent Mycobacterium tuberculosis in human macrophages. Infect. Immun. 73, 3783-3786.

Onodera, S., Suzuki, K., Matsuno, T., Kaneda, K., Takagi, M., Nishihira, J., 1997. Macrophage migration inhibitory factor induces phagocytosis of foreign particles by macrophages in autocrine and paracrine fashion. Immunology 92 , 131-137.

Ottaviani, E., 2006. Molluscan immunorecognition. Invert. Survey J. 3, 50-63.

Pallavicini, A., Costa, M.M., Gestal, C., Dreos, R., Figueras, A., Venier, P., Novoa, B., 2008. High sequence variability of myticin transcripts in hemocytes of immunestimulated mussels suggests ancient host-pathogen interactions. Dev. Comp. Immunol. 32, 213-226.

Parisi, M.G., Li, H., Toubiana, M., Parrinello, N., Cammarata, M., Roch, P., 2009. Polymorphism of mytilin B mRNA is not translated into mature peptide. Mol. Immunol. 46, 384-392.

Park, E.M., Kim, Y.O., Nam, B.H., Kong, H.J., Kim, W.J., Lee, S.J., Kong, I.S., Choi, T.J., 2008a. Cloning, characterization and expression analysis of the gene for a putative lipopolysaccharide-induced TNF-alpha factor of the Pacific oyster, Crassostrea gigas. Fish Shellfish Immunol. 24, 11-17.

Park, H., Ahn, I.Y., Kim, H., Cheon, J., Kim, M., 2008b. Analysis of ESTs and expression of two peroxiredoxins in the thermally stressed Antarctic bivalve Laternula elliptica. Fish Shellfish Immunol. 25, 550-559.

Parrinello, N., Vizzini, A., Arizza, V., Salerno, G., Parrinello, D., Cammarata, M. Giaramita, F.T., Vazzana, M., 2008. Enhanced expression of a cloned and sequenced Ciona intestinalis TNFalpha-like (CiTNF alpha) gene during the LPSinduced inflammatory response. Cell Tissue Res. 334, 305-317.

Pastrana, D.V., Raghavan, N., FitzGerald, P., Eisinger, S.W., Metz, C., Bucala, R. Schleimer, R.P., Bickel, C., Scott, A.L., 1998. Filarial nematode parasites secrete a homologue of the human cytokine macrophage migration inhibitory factor. Infect. Immun. 66, 5955-5963.
Prieto-Lafuente, L., Gregory, W.F., Allen, J.E., Maizels, R.M., 2009. MIF homologues from a filarial nematode parasite synergize with IL-4 to induce alternative activation of host macrophages. J. Leukoc. Biol. 85, 844-854.

Roberts, S., Goetz, G., White, S., Goetz, F., 2009. Analysis of genes isolated from plated hemocytes of the Pacific oyster, Crassostreas gigas. Mar. Biotechnol. (NY) $11,24-44$.

Roberts, S., Gueguen, Y., de Lorgeril, J., Goetz, F., 2008. Rapid accumulation of an interleukin 17 homolog transcript in Crassostrea gigas hemocytes following bacterial exposure. Dev. Comp. Immunol. 32, 1099-1104.

Roger, T., Ding, X., Chanson, A.L., Renner, P., Calandra, T., 2007. Regulation of constitutive and microbial pathogen-induced human macrophage migration inhibitory factor (MIF) gene expression. Eur. J. Immunol. 37, 3509-3521.

Roger, T., Froidevaux, C., Martin, C., Calandra, T., 2003. Macrophage migration inhibitory factor (MIF) regulates host responses to endotoxin through modulation of Toll-like receptor 4 (TLR4). J. Endotoxin Res. 9, 119-123.

Romero, A., Dios, S., Poisa-Beiro, L., Costa, M.M., Posada, D., Figueras, A., Novoa, B. 2011. Individual sequence variability and functional activities of fibrinogenrelated proteins (FREPs) in the Mediterranean mussel (Mytilus galloprovincialis) suggest ancient and complex immune recognition models in invertebrates. Dev. Comp. Immunol. 35, 334-344.

Song, L., Xu, W., Li, C., Li, H., Wu, L., Xiang, J., Guo, X., 2006. Development of expressed sequence tags from the Bay Scallop, Argopecten irradians irradians. Mar. Biotechnol. (NY) 8, 161-169.

Sonthi, M., Toubiana, M., Pallavicini, A., Venier, P., Roch, P., 2011. Diversity of coding sequences and gene structures of the antifungal peptide mytimycin (MytM) from the Mediterranean mussel, Mytilus galloprovincialis. Mar. Biotechnol. (NY).

Sun, H.W., Bernhagen, J., Bucala, R., Lolis, E., 1996. Crystal structure at 2.6-A resolution of human macrophage migration inhibitory factor. Proc. Natl. Acad. Sci. USA 93, 5191-5196.

Swope, M.D., Lolis, E., 1999. Macrophage migration inhibitory factor: cytokine, hormone, or enzyme? Rev. Physiol. Biochem. Pharmacol. 139, 1-32.

Torreilles, J., Guérin, M.-C., Roch, P., 1999. Modified Alsever's solution is not a good medium for reactive oxygen metabolite study in bivalves. Fish Shellfish Immunol. 8, 65-69.

Umemiya, R., Hatta, T., Liao, M., Tanaka, M., Zhou, J., Inoue, N., Fujisaki, K., 2007. Haemaphysalis longicornis: molecular characterization of a homologue of the macrophage migration inhibitory factor from the partially fed ticks. Exp. Parasitol. 115, 135-142.

Venier, P., De Pitta, C., Bernante, F., Varotto, L., De Nardi, B., Bovo, G., Roch, P., Novoa B., Figueras, A., Pallavicini, A., Lanfranchi, G., 2009. MytiBase: a knowledgebase of mussel (M. galloprovincialis) transcribed sequences. BMC Genomics 10, 72.

Venier, P., Pallavicini, A., De Nardi, B., Lanfranchi, G., 2003. Towards a catalogue of genes transcribed in multiple tissues of Mytilus galloprovincialis. Gene 314, 2940.

Venier, P., Varotto, L., Rosani, U., Millino, C., Celegato, B., Bernante, F., Lanfranchi, G., Novoa, B., Roch, P., Figueras, A., Pallavicini, A., 2011. Insights into the innate immunity of the Mediterranean mussel Mytilus galloprovincialis. BMC Genomics $12,69$.

Wang, B., Zhang, Z., Wang, Y., Zou, Z., Wang, G., Wang, S., Jia, X., Lin, P., 2009a. Molecular cloning and characterization of macrophage migration inhibitory factor from small abalone Haliotis diversicolor supertexta. Fish Shellfish Immunol. 27, 57-64.

Wang, L., Song, L., Zhao, J., Qiu, L., Zhang, H., Xu, W., Li, H., Li, C., Wu, L., Guo, X. 2009b. Expressed sequence tags from the zhikong scallop (Chlamys farreri): discovery and annotation of host-defense genes. Fish Shellfish Immunol. 26, 744-750.

Wu, Z., Boonmars, T., Nagano, I., Nakada, T., Takahashi, Y., 2003. Molecular expression and characterization of a homologue of host cytokine macrophage migration inhibitory factor from Trichinella spp. J. Parasitol. 89, 507-515.

Yu, Y., Qiu, L., Song, L., Zhao, J., Ni, D., Zhang, Y., Xu, W., 2007. Molecular cloning and characterization of a putative lipopolysaccharide-induced TNF-alpha factor (LITAF) gene homologue from Zhikong scallop Chlamys farreri. Fish Shellfish Immunol. 23, 419-429. 